\title{
Speed Analysis Approach to Evaluate Traffic Congestion in Pabna Town
}

\author{
Md. Tufajjal Hossain*, Md. Kamrul Hasan \\ Department of Urban \& Regional Planning, Pabna University of Science and Technology, Pabna, Bangladesh \\ Email address: \\ tufajja191@gmail.com (Md. T. Hossain), kanak.planner@gmail.com (Md. K. Hasan) \\ ${ }^{*}$ Corresponding author
}

To cite this article:

Md. Tufajjal Hossain, Md. Kamrul Hasan. Speed Analysis Approach to Evaluate Traffic Congestion in Pabna Town. Urban and Regional Planning. Vol. 4, No. 1, 2019, pp. 39-47. doi: 10.11648/j.urp.20190401.14

Received: March 11, 2019; Accepted: April 29, 2019; Published: May 26, 2019

\begin{abstract}
During the last decades urban migration rate has broken all records in Bangladesh due to several factors like climatic changes, increase in national income, technological advancements etc. These unusual urban dwellers create pressure on travel pattern within the cities. As a result intensive traffic flow has become a common scenario in almost every city in Bangladesh which creates severe traffic congestion that brings speechless woe for citizens. This situation challenges transportation planners and engineers to provide sustainable traffic management strategies to manage traffic congestion. This study has been conducted to measure the intensity of traffic congestion of Pabna town and to identify the traffic congestion spot within the town. Spot speed study and journey and delay studies were the main methodological approaches to conduct the study. The data collected has been analyzed through the use of different statistical computer packages. The study has explored that the average speed of Pabna town has found $13.67 \mathrm{~K}$. P. H with average delays of 3.38 minutes or 203 seconds for a single journey. Pachmatha morr has been identified as the most congested prone intersection of the town. The study has also found that pedestrians movement on the streets due to unavailable footpath, unauthorized hawkers alongside the streets, illegal parking on streets, loading and unloading of passengers by auto-rickshaw and cycle rickshaw, right diverging and cross movement of traffic flow at intersections are the major causes of creating traffic congestion in the town. The suggestion from the study is one-way traffic flow and strict implementation of traffic regulation as a possible solution of congestion for the town.
\end{abstract}

Keywords: Traffic Congestion, Traffic Flow Analysis, Speed Studies, Traffic Engineering, Pabna

\section{Introduction}

Traffic congestion occurs when traffic is delayed because of the presence of excessive vehicles on a road way at a particular time resulting into slower than the normal or "free flow" speeds. [1] During traffic congestion a long queue is formed on a road which causes vehicles in a start and stop state because the number of vehicles exceeds the design capacity of the road. As a result, vehicles trying to use the road suffer delay and travellers can't move within desired time. [2-8].

In Dhaka city, the major share of road space remains occupied by the small capacity vehicles which subsequently has amplified traffic congestion, travel delay and accidents. The total road network is $3000 \mathrm{~km}$ (with only $450 \mathrm{~km}$ primary and secondary/collector roads). Bus services in the city are on a level of baby compared with other cities. Today's bus operation in Dhaka is characterized with the existence of 750 individual bus owners. Besides bus drivers are uneducated. So they are not capable enough to understand traffic signs, warning signs, informatory signs etc. The non-existence of qualified traffic engineering professionals is also a barrier in reducing traffic congestion. Illegal car parking is also responsible for traffic congestion. [9].

Traffic congestion always has negative effects on lives and environment and to quantify these negative effects is complex and multivariate. [10] Traffic congestion wastes time and energy, causes pollution and stress, decreases 
productivity and imposes costs on society. [11].

In recent time, traffic congestion problem has become one of the most costly problems in many cities all over the world. [12] It severely threatens the economy as well as the environment. [13-14] The confederation of British Industry of UK notified that 200 million days were wasted as a result of illness in 1998 costing $\$ 10.2$ million to industry. [15] In Bangladesh, for the year 1997 country wise annual economic loss became $\$ 79$ million due to traffic congestion. [16] Annually $\$ 3$ billion and daily over 8 million works hour is wasted due to traffic congestion in Bangladesh. [17, 9] In USA, drivers in metropolitan areas suffered average 27 hours of traffic delay in 2000, a rise from 7 hours in 1980. [18]

This study has been conducted to measure the intensity of traffic congestion within Pabna town by using spot speed and delay studies. The study also approaches to reveal traffic congestion characteristics within Pabna municipality, an ancient urban area of Bangladesh. However, for insufficient technological facilities technical methods of data collection has not been possible to apply. Hence, all data has been collected manually. So, there could be a chance of unwilling errors.

\section{Materials and Methods}

In order to conduct the study, the measurement of traffic congestion, its impacts on economy as well as environment and recent issues related to traffic congestions are studied. This helps to understand the insight of the problem thoroughly. Objectives of the study are set to expose the characteristics and intensity of traffic congestion. The study has been conducted based on primary and secondary data. Primary data sources are - Reconnaissance survey, Spot Speed Survey and Running Speed and Journey Speed Study or Delay Studies. Spot speeds of vehicles have been surveyed through direct-timing procedure; and moving observer method has been used for the measurements of running speed and journey speed.

The secondary data have been collected from journals, books, Pabna municipality etc. The collected data have been analyzed through the use of ArcGIS 10.3 and statistical computer packages.

\section{Selection of the Study Area}

Pabna is a secondary town in Bangladesh. It is situated at the north western part in Bangladesh. It is a town of Pabna district under Rajshahi division, one of eight divisions of Bangladesh. The town is the administrative capital of Pabna district.

Pabna municipality has an area of about 27 square kilometers and population of 133403. [19] It has a road network of $187.50 \mathrm{~km}$, among $75 \%$ has bitumen surface, in the jurisdiction of different agencies like Pabna Municipality, Roads and Highway Department (RHD) and Local Government Engineering Department (LGED). [20].

Both motorized and non-motorized vehicles are observed in the town. Recent invented Auto rickshaw (also known as Borak) driven through charger battery dominants in the traffic scene of the town. Besides cycle rickshaw driven through both manually and charger battery, motorcycle, CNG, bicycle, bus, minibus, microbus, truck are also observed on the municipality roads.

Major roads of Pabna Municipality are - Abdul Hamid Road, Ataikula Road, Thana Road/Hospital Road, College Road, Gashpara Road, By Pass Road, Pabna-Nagarbari Road, Police Line Road, D. C. Road and Stadium Road. Among these Abdul Hamid Road and Ataikula Road are the busiest roads in the town. Traffic congestion on these two roads has become a common daily scenario. These because five major intersections of Pabna town are located within the two roads which are - Chapa-Bibi Masjid Morr (CMM) intersection, Pachmatha Morr (PMM) intersection, Kheyaghat Morr (KGM) intersection, Traffic Morr (TM) intersection and Indira Morr (IM) intersection. This study has been conducted to analyze traffic congestion on these five intersections.

\section{Results and Discussions}

\subsection{Spot Speed Analysis}

Spot speed is the instantaneous speed of a vehicle at a specified point as it passes the point. Spot speed is calculated by dividing the length of the specified point by time taken by the vehicle to approach it. Spot speed data are useful to determine the problems arisen due to traffic congestion on road and to relate the capacity of road with speeds of vehicles.

However, in this study spot speeds of CMM-PMM section of Ataikula road and TM-IM section of A.H road are calculated separately. It is assumed that the spot speed of PMM-KGM section and KGM-TM section would remain same as CMM-PMM section and TM-IM section respectively. Moreover, the length of CMM-PMM section and TM-IM section are measured as $188 \mathrm{ft}$ or $0.06 \mathrm{~km}$ and $425 \mathrm{ft}$ or $0.13 \mathrm{~km}$ respectively.

\subsubsection{For Ataikula Road}

i. Average Speed of Vehicles

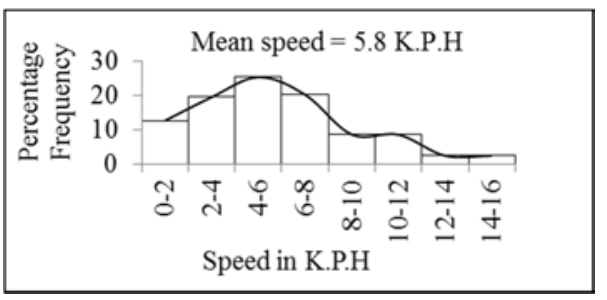

Figure 1. Spot speed frequency distribution curve for CMM-PMM section.

Speed data collected from spot speed survey has grouped into speed-class intervals and the number of vehicles with each class intervals has counted to prepare a frequency distribution table. From the table, arithmetical mean of all speeds has calculated which represents the average speed and a histogram of speed-class intervals against percentage frequency of speed of vehicles has developed [Figure 1].

The average speed of vehicles on CMM-PMM section is 
calculated 5.8 K.P.H with a standard deviation of 3.74 K.P.H. It means that speeds of vehicles goes very low during acute traffic congestion.

Figure 1 shows that speeds of vehicles have no tendency to cluster to the mean value and the frequency drops very slightly with the deviation of speed from the mean value. This exposes that there are considerable vehicles in this section travelling with both high speed and low speed.

ii. Cumulative Speed Distribution Curve

The cumulative speed distribution curve for CMM-PMM section of Ataikula road has constructed by plotting the upper limits of speed-class intervals from frequency distribution table on $\mathrm{X}$ - axis and the cumulative percentage frequency with each class intervals on $\mathrm{Y}$-axis [Figure 2].

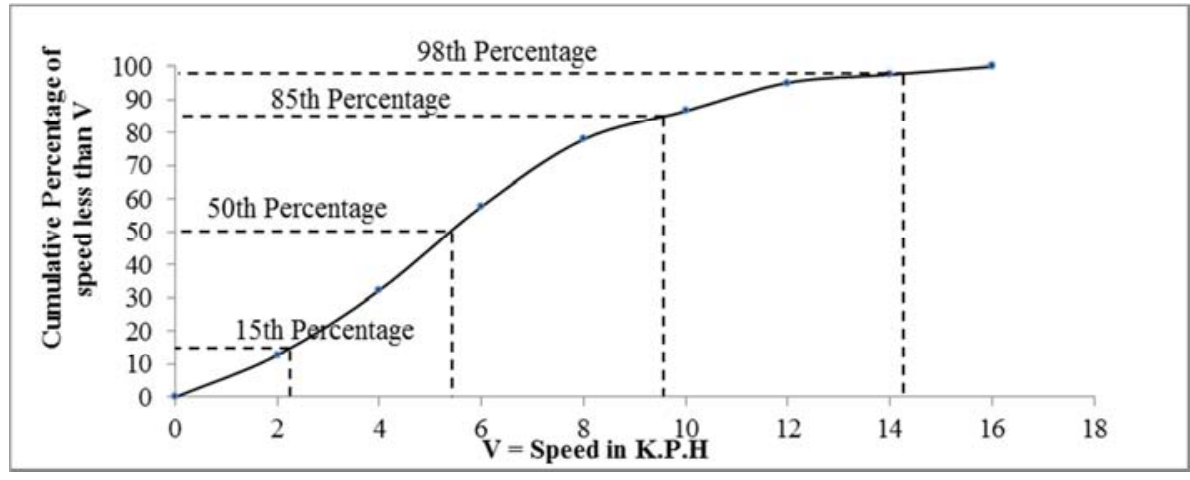

Figure 2. Cumulative speed distribution curve for CMM-PMM section.

The curve in Figure 2 shows the following percentile speed-

(i) $98^{\text {th }}$ percentile speed as 14.34 K.P.H means $98 \%$ of all the vehicles on CMM-PMM section travel at 14.34 K.P.H speed. It may be used as design speed in geometric design for Ataikula road.

(ii) $85^{\text {th }}$ percentile speed or safe speed as 9.63 K.P.H means $85 \%$ of all vehicles travel at a speed of 9.63 K.P.H or only $15 \%$ drivers can drive faster than the safe speed.

(iii) $50^{\text {th }}$ percentile speed or medium speed as 5.39 K.P.H at which there are as many vehicles considered to be driven fasters as there are driven slower.

(iv) $15^{\text {th }}$ percentile speed as 2.23 K.P.H represents the lower speed limit for Ataikula road. This speed should be prohibited for CMM-PMM section to decrease delay and congestion as $85 \%$ drivers are considered to be driving faster than this speed and hence demand for over taking opportunities.

(v) Speed Distribution of Different Types of Vehicles

From the speed data on CMM-PMM section of Ataikula road, mean speed, maximum and minimum speed and standard deviation of speed for individual vehicle are calculated and arranged as a tabular form [Table-1].

Table 1. Speed statistics of different types of vehicles on CMM-PMM section of Ataikula road.

\begin{tabular}{|c|c|c|c|c|c|}
\hline \multirow{2}{*}{ Vehicle Types } & \multicolumn{5}{|c|}{ Speed of Vehicles (K.P.H) } \\
\hline & Mean & Maximum & Minimum & Standard Deviation & Coefficient of variation \\
\hline $\mathrm{CNG}$ & 7.00 & 15.00 & 3.53 & 4.59 & 0.66 \\
\hline Auto-Rickshaw & 4.75 & 15.00 & .42 & 2.75 & 0.58 \\
\hline Rickshaw & 5.71 & 15.00 & .66 & 2.97 & 0.52 \\
\hline Bicycle & 6.71 & 12.00 & .75 & 3.08 & 0.46 \\
\hline Motor cycle & 7.81 & 15.00 & 1.33 & 3.85 & 0.49 \\
\hline Micro-bus & 5.88 & 10.00 & 1.76 & 5.83 & 0.99 \\
\hline Car & 4.69 & 5.45 & 3.16 & 1.32 & 0.28 \\
\hline Others (e.g Van) & 4.68 & 7.50 & 3.33 & 1.50 & 0.32 \\
\hline
\end{tabular}

Table 1 reveals that microbus and $\mathrm{CNG}$ have highest coefficient of variation with a high speed of 15 K.P.H. It means that they could move faster if they don't face any congestion. But they account for very little portion of traffic composition on this road as mentioned above. However, auto-rickshaw and cycle rickshaw, the dominant traffic mode on this section of Ataikula road, have significant coefficient of speed variation. The table exposes that their speed goes very low during congestion. The minimum speed of autorickshaw, cycle rickshaw and bicycle goes very much lower than $15^{\text {th }}$ percentile speed for CMM-PMM section. It means that if long queuing is formed during congestion, these traffic modes make the congestion more acute as other vehicles need over take opportunities while approaching to move.

(vi) Percentage Frequency-Speed Relationship for Individual Vehicle

Percentage frequency-speed relationship graph helps to understand the insight of speed distribution of individual vehicle and to evaluate traffic congestion more efficiently. Percentage frequency-speed relationship graph for individual vehicle are shown in Figure 3. 


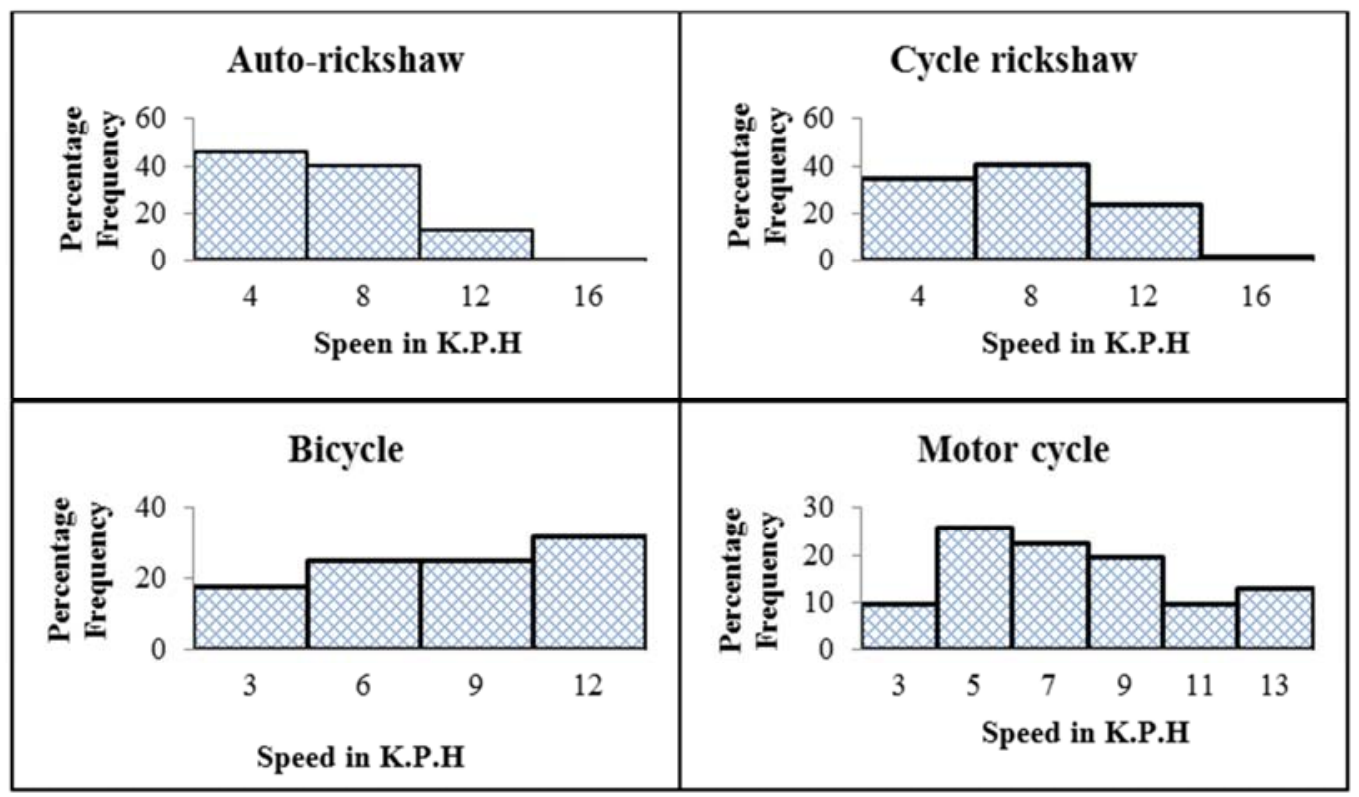

Figure 3. Percentage frequency-speed relationship for individual vehicle.

Figure 3 explains that maximum number of auto-rickshaw travels at comparatively low speed. This happens because there is an unauthorized auto-rickshaw stand at CMM intersection. Drivers tend to loading and unloading passengers by driving slowly and stopping while approaching through this road even at CMM and PMM intersections where respectively right diverging traffic from Boro-Bazar road and cross traffic from Square road or Sonapotti road have already been creating conflict. However, as majority of auto-rickshaw travels nearly $15^{\text {th }}$ percentile speed, it creates blockage for other vehicles and add fuel to the congestion. The figure also shows that significance percentage of cycle rickshaw travels nearly $15^{\text {th }}$ percentile speed. Therefore, it also impacts on congestion by blocking other vehicles. However, majority of other vehicles (e.g. bicycle, motor cycle) travel at comparatively high speed. Therefore, they have less contribution on creating congestion.

(vii) Time mean and Space mean Speed Calculation Time mean speed is the average of all speeds at a point over a period of time while space mean speed is the average of all speeds at an instant of time over a space. Time mean and space mean speed for Ataikula road are calculated as 6.5 K.P.H and 4.19 K.P.H respectively. The variance about space mean speed is 9.68 K.P.H. Concentration rates of vehicles can be understood from these speeds.

\subsubsection{For A.H Road}

i Average Speed of vehicles

From the speed frequency distribution table developed from speed data of TM-IM section of A.H road, arithmetical mean of all speeds has calculated which represents the average speed and a histogram of speed-class intervals against percentage frequency of speed of vehicles has developed [Figure 4].

The average speed of vehicles on TM-IM section is calculated 22.4 K.P.H with a standard deviation of 10 K.P.H. It means that speeds of vehicles significantly vary while travelling the section of the road.

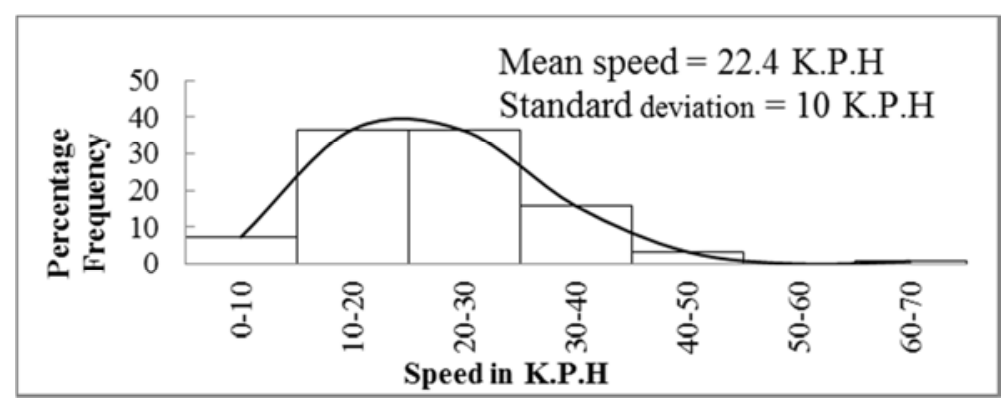

Figure 4. Spot speed frequency distribution curve for CMM-PMM section.

The diagram in Figure 4 shows that speeds of vehicles has tendency to cluster to the mean value and the frequency drops with the deviation of speed from the mean value. This exposes that majority vehicles could move at the average speeds and very few travel below the mean speed. ii Cumulative Speed Distribution Curve

The cumulative speed distribution curve for TM-IM section of A.H road has developed by plotting the upper limits of speed-class intervals from frequency distribution table on $\mathrm{X}$ - axis and the cumulative percentage frequency 
with each class intervals on $\mathrm{Y}$-axis [Figure 5].

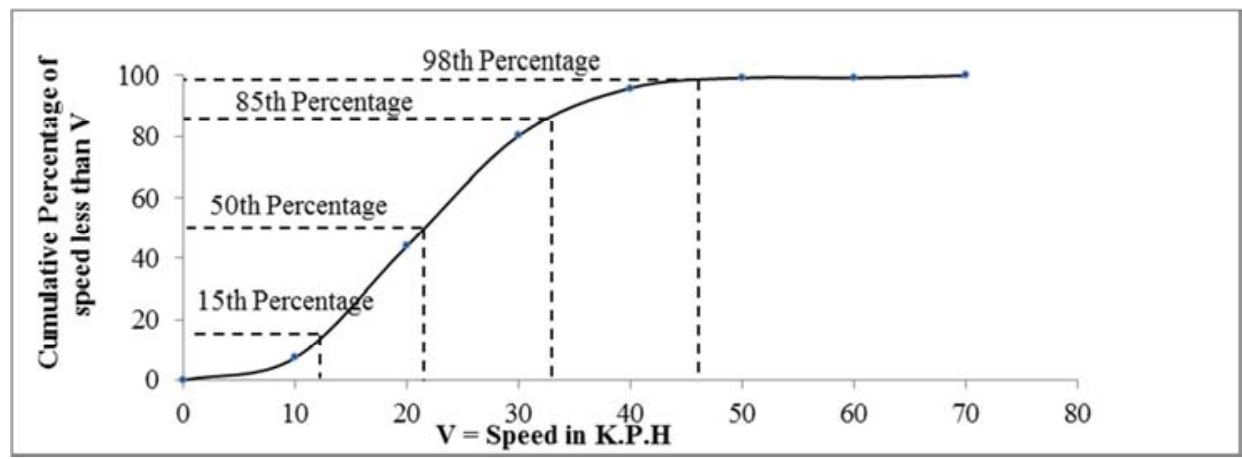

Figure 5. Cumulative speed distribution curve for TM-IM section.

The curve in Figure 5 shows the following percentile speed for TIM-IM section of A.H road-

(i) $98^{\text {th }}$ percentile speed as 46.16 K.P.H means $98 \%$ of all the vehicles on TM-IM section travel at 46.16 K.P.H speed. It may be used as design speed in geometric design for A.H road.

(ii) $85^{\text {th }}$ percentile speed or safe speed as 33.03 K.P.H means $85 \%$ of all vehicles travel at a speed of 33.03 K.P.H or only $15 \%$ drivers can drive faster than the safe speed.

(iii) $50^{\text {th }}$ percentile speed or medium speed as 21.67 K.P.H at which there are as many vehicles considered to be driven fasters as there are driven slower.

(iv) $15^{\text {th }}$ percentile speed as 12.1 K.P.H represents the lower speed limit for A.H road. This speed should be prohibited for TM-IM section to decrease delay and congestion as $85 \%$ drivers are considered to be driving faster than this speed and hence demand for over taking opportunities.

iii Speed Distribution of Different Types of Vehicles

From the speed data on CMM-PMM section of Ataikula road, mean speed, maximum and minimum speed and standard deviation of speed for individual vehicle are calculated and arranged as a tabular form [Table-2].

Table 2. Speed statistics of different types of vehicles on TM-IM section of A.H road.

\begin{tabular}{llllll}
\hline \multirow{2}{*}{ Vehicle Types } & \multicolumn{3}{l}{ Speed of Vehicles (K.P.H) } & & \\
\cline { 2 - 6 } & Mean & Maximum & Minimum & Standard Deviation & Coefficient of variation \\
\hline CNG & 22.51 & 32.50 & 10.00 & 6.11 & 0.27 \\
Auto-Rickshaw & 18.34 & 43.33 & 9.29 & 6.51 & 0.36 \\
Rickshaw & 20.06 & 43.33 & 7.22 & 8.25 & 0.41 \\
Bicycle & 23.71 & 32.50 & 8.13 & 7.41 & 0.31 \\
Motor cycle & 26.28 & 65.00 & 8.13 & 10.79 & 0.41 \\
Bus & 18.88 & 21.67 & 16.25 & 2.72 & 0.14 \\
Micro-bus & 25.91 & 43.33 & 10.00 & 9.06 & 0.35 \\
Car & 19.99 & 43.33 & 8.13 & 7.90 & 0.4 \\
Truck & 19.06 & 32.50 & 8.67 & 10.20 & 0.54 \\
Others (e.g Van) & 10.00 & 10.00 & 10.00 & 0 & 0 \\
\hline
\end{tabular}

Table 2 reveals that speed of truck varies in a large scale while travelling through TM-IM section of the road with high speed of 32.50 K.P.H. It means truck have opportunities to travel at high speed if it doesn't face any congestion. Again, speeds of rickshaws and motor cycles are also significantly affected as they have high coefficient of speed variation. Cross movement of rickshaw and motor cycle from Rupkotha road creates conflict at IM intersection and decreases their speeds resulting congestion on the road. On the other hand, bus has the lowest coefficient of speed variation and only its minimum speed is greater than the $15^{\text {th }}$ percentile speed for TM-IM section of A.H road. It explains that all other vehicles except bus try to overtake each other according to their speed acceleration capability and creates horrible traffic congestion.

iv Percentage frequency-Speed Relationship

Percentage frequency-speed relationship graph for dominant traffic mode of TM-IM section of A.H road are shown in Figure 6.
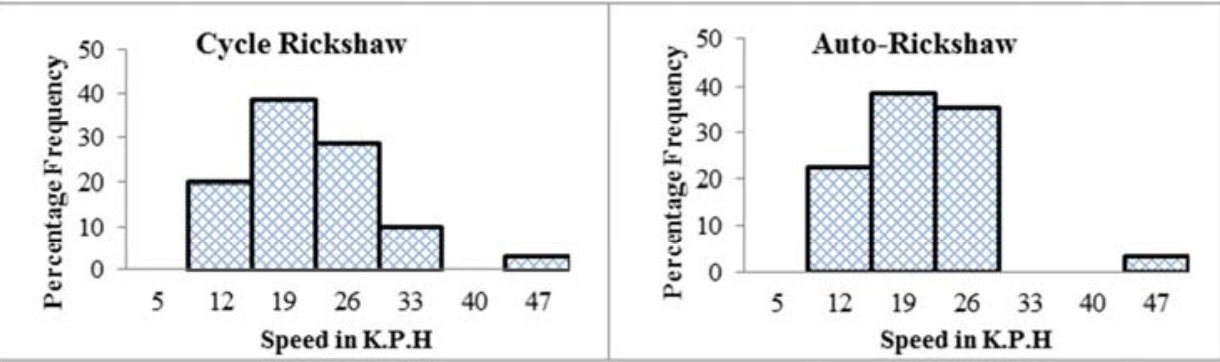


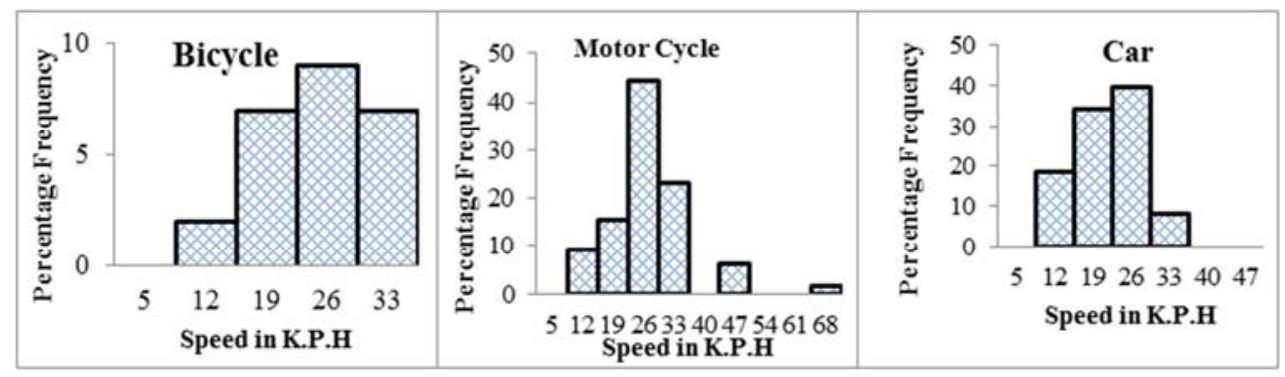

Figure 6. Percentage frequency-speed relationship for individual vehicle.

Figure 6 explains that majority of these vehicles travels at speed more than $15^{\text {th }}$ percentile speed. Therefore, congestion on this section doesn't occur for speed of individual traffic mode although there is considerable percentage of autorickshaw and cycle rickshaw travel at $15^{\text {th }}$ percentile speed. Diverging or merging and cross movement of auto-rickshaw, cycle rickshaw and motor cycle from Aurangzeb road or Rupkotha road create conflict at IM intersections resulting acute congestion during peak hour. Again, waving movement of auto-rickshaw, cycle rickshaw and motor cycle at TM intersection are also responsible for creating congestion. Unavailable footpath, unauthorized hawkers on footpath, pedestrian flow create bottleneck condition which are mainly responsible to decrease up to the minimum speed of these vehicles. So, traffic congestion on this section of A.H road can be minimized through better traffic management system. v Time mean and Space mean Speed Calculation

Time mean and space mean speed for A.H road are calculated as 21.78 K.P.H and 16.61 K.P.H respectively. The variance about space mean speed is 85.87 K.P.H. Concentration rates of vehicles can be understood from these speeds data.

\subsection{Journey Speeds and Delays Analysis}

In order to analyze Journey Speeds and Delays, six runs for both directions have made with auto-rickshaw between CMM and IM intersections of Ataikula road and A.H road. Average of six runs in both directions is given in Table-3.

Table 1. Delay Time Table while travelling in both directions.

\begin{tabular}{|c|c|c|c|c|c|c|}
\hline \multicolumn{7}{|c|}{ CMM-IM Direction } \\
\hline \multirow[b]{2}{*}{ Sections } & \multirow{2}{*}{$\begin{array}{l}\text { Average } \\
\text { Journey } \\
\text { Time (min) }\end{array}$} & \multirow{2}{*}{$\begin{array}{l}\text { Average } \\
\text { Stopped } \\
\text { Time (min) }\end{array}$} & \multirow{2}{*}{$\begin{array}{l}\text { Vehicles met with in } \\
\text { the opposing } \\
\text { direction (in PCU) }\end{array}$} & \multicolumn{2}{|c|}{ Same Direction Traffic (on Average) } & \multirow{2}{*}{$\begin{array}{l}\text { Number of vehicles } \\
\text { parking on streets } \\
\text { (on average) }\end{array}$} \\
\hline & & & & $\begin{array}{l}\text { Overtaking } \\
\text { Vehicles }\end{array}$ & $\begin{array}{l}\text { Vehicles passed by } \\
\text { the test Vehicle }\end{array}$ & \\
\hline CMM & 0.28 & 0.16 & 9.83 & 1 & 1 & 2 \\
\hline CMM-PMM & 1.1 & 0.4 & 16.08 & 4 & 4 & 3 \\
\hline PMM & 0.05 & 0.01 & 5.21 & 1 & 1 & 1 \\
\hline PMM-KGM & 2.16 & 1.32 & 10.08 & 2 & 2 & 6 \\
\hline KGM & 0.18 & 0.08 & 2.58 & 1 & 1 & 3 \\
\hline KGM-TM & 0.48 & 0.11 & 12.42 & 1 & 2 & 11 \\
\hline TM & 0.08 & 0.01 & 18.21 & 2 & 1 & 7 \\
\hline TM-IM & 0.74 & 0.29 & 96.13 & 5 & 11 & 19 \\
\hline $\mathrm{IM}$ & 0.17 & 0.08 & 25.75 & 1 & 1 & 9 \\
\hline \multicolumn{7}{|c|}{ IM-CMM Direction } \\
\hline IM & 0.14 & 0.01 & 18.21 & 2 & 3 & 5 \\
\hline IM-TM & 0.66 & 0.01 & 80 & 5 & 14 & 13 \\
\hline $\mathrm{TM}$ & 0.16 & 0.04 & 7.17 & 1 & 1 & 5 \\
\hline TM-KGM & 0.36 & 0.14 & 15.33 & 3 & 1 & 2 \\
\hline KGM & 0.15 & 0.17 & 8.13 & 1 & 2 & 2 \\
\hline KGM-PMM & 0.97 & 0.32 & 13.58 & 1 & 7 & 4 \\
\hline PMM & 0.25 & 0.1 & 7.58 & 2 & 2 & 2 \\
\hline PMM-CMM & 0.46 & 0.06 & 12.67 & 2 & 5 & 4 \\
\hline $\mathrm{CMM}$ & 0.19 & 0.07 & 6 & 1 & 2 & 3 \\
\hline
\end{tabular}

Table 3 shows that both journey time and delay time while travelling in both directions are high for PMM to KGM section with a considerable opposite traffic. It represents jammed condition on this section as there is an auto-rickshaw stand nearer to the KGM intersection. Therefore, there are also significant numbers of parked vehicles found while travelling through this section from both directions. On the other hand, the least journey time and delay time are found at TM intersection while travelling from CMM to IM direction and at IM intersection while travelling from IM to CMM direction. Again, significant number of opposite traffic and parked vehicles are found for TM to IM section of A.H road for both directions movement.

Running Speed and Journey Speed Calculation

Running speed and journey speed are calculated from Table- 3 by calculating flow, mean journey time and mean delay time [Table 4]. 
Table 2. Journey speed and running speed calculation.

\begin{tabular}{|c|c|c|c|c|c|c|c|}
\hline \multicolumn{8}{|c|}{ CMM-IM Direction } \\
\hline Sections & Sections Type & Length (m) & $\begin{array}{l}\text { Flows (PCU } \\
\text { /hr) }\end{array}$ & $\begin{array}{l}\text { Mean journey time } \\
\text { (min) }\end{array}$ & $\begin{array}{l}\text { Mean running time } \\
\text { (min) }\end{array}$ & $\begin{array}{l}\text { Running } \\
\text { Speed (K.P.H) }\end{array}$ & $\begin{array}{l}\text { Journey } \\
\text { Speed (K.P.H) }\end{array}$ \\
\hline CMM & Intersection & 8.2 & 766 & 0.28 & 0.12 & 4.1 & 1.76 \\
\hline CMM-PMM & Route & 45.58 & 487 & 1.1 & 0.7 & 3.91 & 2.49 \\
\hline PMM & Intersection & 5.19 & 1516 & 0.05 & 0.04 & 7.79 & 6.23 \\
\hline PMM-KGM & Route & 86.49 & 260 & 2.16 & 0.84 & 6.18 & 2.4 \\
\hline KGM & Intersection & 7.18 & 1478 & 0.18 & 0.1 & 4.31 & 2.39 \\
\hline KGM-TM & Route & 23.15 & 1024 & 0.54 & 0.43 & 3.23 & 2.57 \\
\hline TM & Intersection & 21.37 & 2043 & 0.05 & 0.04 & 32.06 & 25.64 \\
\hline TM-IM & Route & 131.26 & 3171 & 0.85 & 0.56 & 14.06 & 9.27 \\
\hline $\mathrm{IM}$ & Intersection & 24 & 3525 & 0.17 & 0.09 & 16 & 8.47 \\
\hline \multicolumn{8}{|c|}{ IM-CMM Direction } \\
\hline IM & Intersection & 24 & 4790 & 0.15 & 0.14 & 10.29 & 9.6 \\
\hline IM-TM & Route & 131.26 & 3734 & 0.8 & 0.79 & 9.97 & 9.84 \\
\hline TM & Intersection & 21.37 & 4553 & 0.16 & 0.12 & 10.69 & 8.01 \\
\hline TM-KGM & Route & 23.15 & 1030 & 0.24 & 0.1 & 13.89 & 5.79 \\
\hline KGM & Intersection & 7.18 & 287 & 0.36 & 0.19 & 2.27 & 1.2 \\
\hline KGM-PMM & Route & 86.49 & 78 & 5.59 & 5.27 & 0.98 & 0.93 \\
\hline PMM & Intersection & 5.19 & 1042 & 0.25 & 0.15 & 2.08 & 1.25 \\
\hline PMM-CMM & Route & 45.58 & 503 & 0.82 & 0.76 & 3.6 & 3.34 \\
\hline CMM & Intersection & 8.2 & 1127 & 0.24 & 0.17 & 2.89 & 2.05 \\
\hline
\end{tabular}

Journey speed is the effective speed of vehicles over a course while running speed is the average speed of vehicles while it is in motion. Therefore, perception of delays for a course can be gained from these speeds. For better understanding of running speed and journey speed they can be compared in multiple line graph [Figure 7].

While travelling from CMM to IM direction, Figure 7 shows that running speed becomes notably higher than journey speed in between TM to IM section of the course. It means that vehicles have to face serious delays while travelling to IM from TM intersection. Again, significant variation between running speed and journey speed is also seen while travelling from CMM to KGM intersection which represents delays in the course. On the other hand, running speed and journey speed are found almost same for KGM to TM section of the course. That means vehicles move this section facing less delays.

Furthermore, for the course from IM to CMM direction large difference has found between IM to KGM section indicating woeful delays. Again, slight difference has found between running speed and journey speed while travelling through $\mathrm{KGM}$ to $\mathrm{CMM}$ section of the course meaning less delays.

For the journey to IM direction from CMM, vehicles have to face diverging traffic from Boro-Bazar road at CMM intersection and cross traffic from Square road and Sonapotti road at PMM intersection which makes journey speed less than the running speed for CMM to KGM section of the course. On the other hand, vehicles have face congestion that makes difference between their running speed and journey speed in TM to IM section of the course.

But for the journey to CMM from IM, vehicles have to face cross traffic from Rupkotha road and merging traffic from Aurangzeb road at IM intersection, congestion in IM to TM section and waving traffic at TM intersection that makes a lot of difference between running speed and journey speed for IM to KGM section of the course. On the other hand, for KGM to CMM part of the course vehicles face waiting traffic in between KGM to PMM section, cross traffic at PMM intersection and waiting traffic at $\mathrm{CMM}$ intersection that makes slight difference between running speed and journey speed of vehicles.

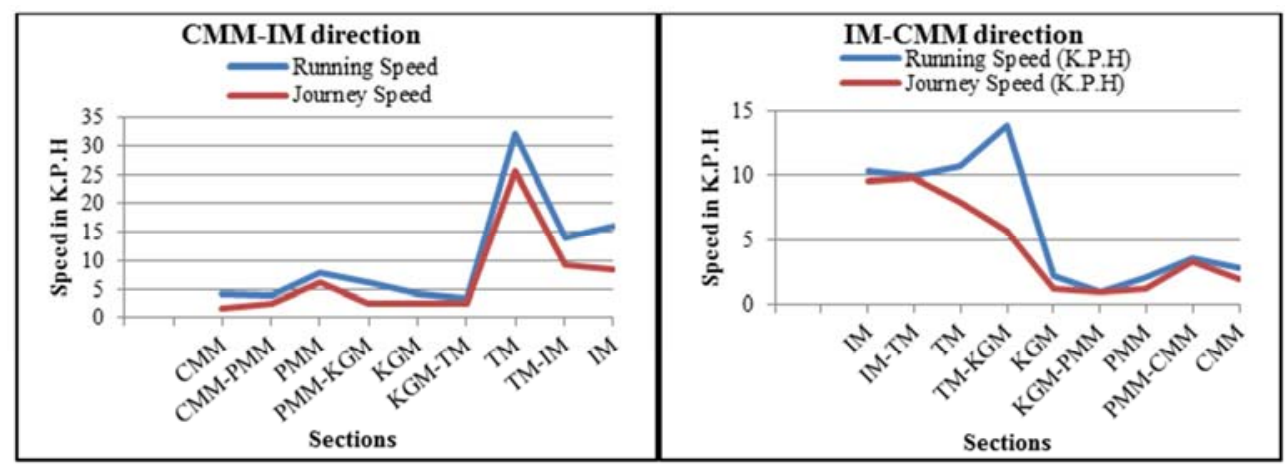

Figure 7. Comparison between running speed and journey for both directions.

Therefore, running speed and journey speed for a single journey of CMM to KGM direction are respectively 5.13 K.P.H and 
2.43 K.P.H with 1.89 minutes delay and of KGM to CMM direction are 1.37 K.P.H and 1.26 K.P.H with 0.55 minutes delay [Table-5].

Table 3. Running speed and journey speed for CMM-KGM and KGM-IM section.

\begin{tabular}{|c|c|c|c|c|c|c|c|}
\hline \multicolumn{8}{|c|}{ Travelling between CMM to KGM } \\
\hline Direction & $\begin{array}{l}\text { Length } \\
\text { (m) }\end{array}$ & $\begin{array}{l}\text { Flows } \\
(\mathrm{PCU} / \mathrm{hr})\end{array}$ & $\begin{array}{l}\text { Mean journey } \\
\text { time (min) }\end{array}$ & $\begin{array}{l}\text { Average stopped } \\
\text { time (min) }\end{array}$ & $\begin{array}{l}\text { Mean running } \\
\text { time }\end{array}$ & $\begin{array}{l}\text { Running Speed } \\
\text { (K.P.H) }\end{array}$ & $\begin{array}{l}\text { Journey Speed } \\
\text { (K.P.H) }\end{array}$ \\
\hline CMM-KGM & \multirow{2}{*}{145.46} & 3029 & 3.59 & 1.89 & 1.7 & 5.13 & 2.43 \\
\hline KGM-CMM & & 2750 & 6.9 & 0.55 & 6.35 & 1.37 & 1.26 \\
\hline \multicolumn{8}{|c|}{ Travelling between KGM to IM } \\
\hline KGM-IM & 20606 & 11241 & 1.79 & 0.57 & 1.22 & 10.18 & 4.88 \\
\hline IM-KGM & 206.96 & 14394 & 1.71 & 0.37 & 1.34 & 9.27 & 5.1 \\
\hline
\end{tabular}

On the other hand, running speed and journey speed for a single journey of KGM to IM direction are respectively 10.18 K.P.H and 4.88 K.P.H with 0.57 minutes delay and of IM to KGM direction are 9.27 K.P.H and 5.1 K.P.H with 0.37 minutes delay [Table-5].

\section{Conclusion}

Traffic congestion analysis of the town has exposed that auto-rickshaw, cycle rickshaw, bicycle and motor cycle are the popular traffic mode and significant variation of speed for different vehicles represents congestion and delays. The average speed of the town is calculated about 13.67 K.P.H with average delays of about 3.38 minutes or 203 seconds for a single journey to and from the downtown area although it varies largely from road to road.

Congestion in Pabna town is occurred due to many factors like pedestrians movement on the streets because of unavailable footpath, unauthorized hawkers alongside the streets, illegal parking on streets, loading and unloading of passengers by auto-rickshaw and cycle rickshaw etc. Right diverging and cross movement of traffic flow at intersections are also responsible for creating congestion.

One-way traffic flow can be a possible solution of congestion for the town. But it can be predicted that alternative roadway would be demanded in nearest future especially for buses, trucks and microbus. Controlling of traffic flow at intersections can be also a possible way to reduce congestion rate. Number of vehicles approaching intersection like traffic more form each road can be controlled to minimize congestion.

\section{References}

[1] Systematics, C. (2005). Traffic congestion and reliability: Trends and advanced strategies for congestion mitigation. Final Report, Texas Transportation Institute. http://ops. fhwa. dot. gov/congestion_report_04/index.htm.

[2] Goodwin, P. (2004). The economic costs of road traffic congestion.

[3] Levinson, H. S., Lomax, T. J., \& Turner, S. (1997). Traffic Congestion-Past-Present-Future. In Traffic congestion and traffic safety in the 21 st century: Challenges, innovations, and opportunities.
[4] Lomax, T. J. (1990). Estimating transportation corridor mobility. Transportation Research Record, (1280).

[5] Lomax, T., Turner, S., \& Shunk, G. (1997). Quantifying Congestion. NCHRP Report 398. National Cooperative Highway Research Program. Transportation Research Board, Washington, DC.

[6] Taylor, B. D. (2002). Rethinking traffic congestion. Access Magazine, 1 (21).

[7] Thomson, J. M. (1998). Reflections on the economics of traffic congestion. Journal of transport economics and policy, 93-112.

[8] Weisbrod, G., Vary, D., \& Treyz, G. (2003). Measuring economic costs of urban traffic congestion to business. Transportation Research Record: Journal of the Transportation Research Board, (1839), 98-106.

[9] Chowdhury, T. U., Raihan, S. M., Fahim, A., \& Bhuiyan, M. A. (2016). A Case Study on Reduction of Traffic Congestion of Dhaka City: Banani Intersection. In International Conference on Agriculutural, Civil and Environmental Engineering (ACEE-16).

[10] Olusina, J. O., \& Samson, A. P. (2014). Determination of predictive models for traffic congestion in lagos metropolis. International Journal of Engineering, 5 (02), 8269.

[11] Rao, A. M., \& Rao, K. R. (2012). Measuring Urban Traffic Congestion-A Review. International Journal for Traffic \& Transport Engineering, 2 (4).

[12] Long, J., Gao, Z., Ren, H., \& Lian, A. (2008). Urban traffic congestion propagation and bottleneck identification. Science in China Series F: Information Sciences, 51 (7), 948-964.

[13] Sorensen, P., Wachs, M., Min, E. Y., Kofner, A., \& Ecola, L. (2008). Moving Los Angeles: Short-term policy options for improving transportation. Rand Corporation.

[14] Wang, G., Gao, Z., Xu, M., \& Sun, H. (2014). Joint link-based credit charging and road capacity improvement in continuous network design problem. Transportation Research Part A: Policy and Practice, 67, 1-14.

[15] O'Regan, B., \& Buckley, F. (2003). The psychological effects of commuting in Dublin. Centre for research in management learning and development working paper series.

[16] Osman, S. (2010). Dhaka's Traffic Problem-Opportunities and Suggested Solutions.

[17] Gilbert, R., \& Perl, A. (2013). Transport revolutions: moving people and freight without oil. New Society Publishers. 
[18] Arnott, R., Rave, T., \& Schöb, R. (2005). Alleviating urban traffic congestion. MIT Press Books, 1.

[19] BBS (2005): Statistical Year Book of Bangladesh, Bangladesh Bureau of Statistics (www.bbs.gov.bd), Government of Bangladesh.
[20] MIDP (2008). Municipal Infrastructure Development Plan for Pabna Paurashava, Pabna. 